\title{
Food Insecurity and Sexual Risk in an HIV Endemic Community in Uganda
}

\author{
Cari L. Miller • David R. Bangsberg • \\ David M. Tuller · Jude Senkungu $\cdot$ Annet Kawuma • \\ Edward A. Frongillo · Sheri D. Weiser
}

Published online: 20 April 2010

(C) The Author(s) 2010. This article is published with open access at Springerlink.com

\begin{abstract}
Food insecurity has been linked to high-risk sexual behavior in sub-Saharan Africa, but there are limited data on these links among people living with HIV/AIDS, and on the mechanisms for how food insecurity predisposes individuals to risky sexual practices. We undertook a series of in-depth open-ended interviews with 41 individuals living with HIV/AIDS to understand the impact of food insecurity on sexual-risk behaviors. Participants were recruited from the Immune Suppression Clinic at the Mbarara University of Science and Technology in Mbarara, Uganda. Interviews were recorded, transcribed
\end{abstract}

\section{L. Miller}

Faculty of Health Sciences, Simon Fraser University,

Burnaby, BC, Canada

D. R. Bangsberg · J. Senkungu · A. Kawuma

Mbarara University of Science and Technology, Mbarara,

Uganda

\section{R. Bangsberg}

Ragon Institute of MGH, MIT, and Harvard, Massachusetts General Hospital Center for Global Health, Harvard Medical School, Boston, MA, USA

\section{M. Tuller}

School of Public Health and Graduate School of Journalism, University of California at Berkeley, Berkeley, CA, USA

\section{E. A. Frongillo}

Department of Health Promotion, Education, and Behavior, Arnold School of Public Health, University of South Carolina, Columbia, SC, USA

S. D. Weiser $(\square)$

Division of HIV/AIDS, San Francisco General Hospital and Center for AIDS Prevention Studies, University of California, San Francisco, 995 Potrero Street, Building 80, Box 0874, San Francisco, CA 94110, USA

e-mail: sheri.weiser@ucsf.edu verbatim, translated, and coded following the strategy of grounded theory. Four major themes emerged from the interview data: the relationship between food insecurity and transactional sex for women; the impact of a husband's death from HIV on worsening food insecurity among women and children; the impact of food insecurity on control over condom use, and the relationship between food insecurity and staying in violent/abusive relationships. Food insecurity led to increased sexual vulnerability among women. Women were often compelled to engage in transactional sex or remain in violent or abusive relationships due to their reliance on men in their communities to provide food for themselves and their children. There is an urgent need to prioritize food security programs for women living with HIV/AIDS and address broader gender-based inequities that are propelling women to engage in risky sexual behaviors based on hunger. Such interventions will play an important role in improving the health and wellbeing of people living with HIV/AIDS, and preventing HIV transmission.

Keywords Food insecurity - HIV/AIDS - Uganda · Sexual-risk behavior - Gender - Transactional sex . Violence

\section{Introduction}

Food insecurity, defined as having uncertain or limited availability of nutritionally adequate or safe food or the inability to procure food in socially acceptable ways [1], is an important public policy issue in many settings in subSaharan Africa, and is a leading cause of morbidity and mortality [2]. The HIV/AIDS epidemic in Africa has further undermined food security among populations already 
vulnerable through drought and poverty by creating additional pressures on food production and distribution systems [3]. HIV/AIDS has negatively affected individuals' and communities' ability to produce and harvest food $[4,5]$. In addition, food insecurity and malnutrition can increase the risk of HIV infection following exposure, and accelerate progression to AIDS and death among those infected [6-8]. Recently, the linkage between food insecurity and sexual risk in sub-Saharan Africa has been examined with the aim of supporting the integration of food and HIV/AIDS programming activities where possible [9, 10].

Food insecurity has been postulated as an important cause of sexual risk-taking, particularly among women living in poverty [11-14]. Some studies have examined the relationship between poverty and sex exchange, coerced sex, and inconsistent condom use [15, 16], but few have examined the specific impact of food insecurity on these behaviors. In Nigeria, female sex workers identified poverty and lack of food as conditions that led them to initiate sex work [17]. In a large population-based study from Botswana and Swaziland, food insecurity was associated with inconsistent condom use with a non-primary partner, sex exchange, intergenerational sex, and lack of control in sexual relationships [18].

Age-disparate transactional sex has contributed to the increasing rates of HIV-infection among young women in Africa. Ethnographic research suggests that these transactional sexual relationships help shape women's identities in the context of severe poverty [19]. A study in Tanzania among young people highlighted that transactional sex was commonplace, but that there were gender differences in the motivations for pursuing such activities: men were primarily sexually motivated and women were primarily economically motivated. In addition, women's economic reliance on male sexual partners limits their ability to negotiate safer sexual practices within these transactional sexual relationships [16]. In view of recent evidence that declining rates of HIV in Sub-Saharan Africa are largely seen among the more economically advantaged populations and that HIV threatens to become a disease of the poor, it is particularly important to better understand the ways in which food insecurity and economic disadvantage contribute to HIV transmission dynamics in Uganda and elsewhere in sub-Saharan Africa [20].

Little is known about the specific mechanisms through which food insecurity leads to risky sexual practices in subSaharan Africa, and there are almost no data on how food insecurity impacts sexual practices among HIV-infected individuals. Qualitative research provides an opportunity to gather context-specific data regarding individuals' lived experience, particularly with respect to sensitive and personal topics such as sexual risk-taking. We undertook this qualitative study to understand in context the mechanisms relating food insecurity and sexual risk-taking including transactional sex, primary partner violence, and condom control among women and men living with HIV/AIDS in Uganda.

\section{Methods}

\section{Population and Sample}

We conducted in-depth interviews in August and September 2007 with 41 people living with HIV/AIDS. All participants attended the Immune Suppression (ISS) Clinic in Mbarara, Uganda, which serves as a regional distribution point for free antiretrovirals (ARVs) and draws a largely rural population. Participants were recruited from among ISS Clinic patients who came to the clinic to pick up their monthly supply of ARVs or to receive medical treatment. Participants were selected through purposive sampling methods, based on sex and age-group distribution to ensure that a range of perspectives were represented [21]. Clinic staff, familiar with the personal histories of clinic patients referred potential participants to the investigators. All participants provided written informed consent. Participants received compensation for their time in the form of money to cover the cost of travel to and from clinic. Sample size was determined by theoretical saturation where new categories of concepts no longer emerged.

\section{Data Collection}

Thirty-five of the semi-structured interviews were conducted in English and Runyankole, the main regional language, by one of the study investigators in conjunction with a trained interviewer and interpreter. Six interviews were conducted completely in Runyankole by the trained interviewer alone. Interviews lasted from $30 \mathrm{~min}$ to $2 \mathrm{~h}$, and took place in a private room in the clinic. Interviews were conducted using an interview guide that included semistructured and open-ended questions, followed by probes based on initial responses. Probes were designed to further elicit details and examples pertaining to impacts of food insecurity on health-related behaviors, including sexual practices. The interview guide contained questions on family food security, strategies adopted to secure food, impacts of food insecurity on health-seeking behavior and adherence, gender dynamics in terms of procurement and distribution of household food, and associations between food insecurity and sexual risk-taking. When relevant, participants were asked to describe in detail the mechanisms by which food insecurity could contribute to risky sexual practices and exacerbate gender power imbalances. 
Data Analysis

All interviews were digitally recorded, translated from Runyankole into English, transcribed verbatim, and analyzed using the strategy of open and axial coding [22]. This process involved reviewing, comparing, labeling, and categorizing the data, and putting these findings together by making connections between categories according to a coding strategy that involved conditions, context, interactions, and consequences. An initial review of the interviews was conducted by two of the study investigators, who identified repeated observations in the data and collated those into major themes, each having a number of secondary related themes. A third investigator then reviewed the transcripts and all three investigators resolved coding differences through discussion and debate. In this paper we focus primarily on the relationship between food insecurity and sexual risk-taking and use selected quotations to illustrate key points. Peer debriefing was conducted to ensure trustworthiness of the data [23]. All study procedures received approval from both the University of California San Francisco Committee on Human Research, the Uganda National Council on Science and Technology, and the Mbarara University of Science and Technology (MUST) Institutional Review Board.

\section{Results}

Twenty-five women and 16 men were interviewed for the study. They ranged in age from 24 to 57 , with a mean age of 37 for the women and 40 for the men. Thirty were on antiretroviral therapy (ART), and 11 had not yet initiated ART. Most earned their livelihoods through gardening and farming, and some also sold goods or ran small shops.

Four major themes emerged regarding the impact of food insecurity on sexual risk-taking. First, food insecurity directly contributed to women's decision to engage in transactional sex for food, or for money to buy food. Second, widows were at increased risk of both food insecurity and being approached for transactional sex. Third, food insecurity undermined women's ability to assert control over condom use, even in primary relationships. Fourth, food insecurity was a barrier for women in abusive relationships, particularly among those who were considering leaving their partners.

\section{Food Insecurity as a Basis for Transactional Sex}

Many participants reported that they knew women who had exchanged sex for food or other subsistence goods, and several participants discussed their personal experiences with such offers of exchange. Women acknowledged having received multiple such requests from men. "I know they're doing it not because they like it but because they don't have much of a choice," said a 34-year-old woman who was separated from her husband and lived with her parents. "Especially these days a lot of women don't have anything to eat, so they decide to do some prostitution to earn some money."

According to a 35-year-old widow who makes and sells baskets in an effort to support her three children:

Yes, truly it happens to a lot of women. I've thought about it myself. Most of the time, when I'm desperate for something to eat, something to drink...And then the devil tempts you, and then you see a man, and he's there and you ask yourself, 'If I slept with him, couldn't I get 10,000 shillings [approximately $\$ 5.00$ US] to buy maybe a sack of charcoal?'

Another widow, a 34-year-old with five children, described how the need to alleviate her family's hunger routinely tempted her to give into men who approach her for sex exchange:

Well it [consideration of having sex in exchange for food] has happened to me a number of times, it usually happens when my children are very, very hungry and I have no food and there is no money. And something tells me, 'Why am I rejecting the men, after all, I would be able to feed my children'...

Male participants also understood that lack of sufficient food could lead to transactional sex outside of primary relationships, as a male farmer supporting a 12-person household indicated:

Women who stay in town slum areas, the only thing they benefit from a man is making sure that their day has ended and they are provided for. That is, the women have sex with you so that they get something to drink or eat and that is it...If you decide to find a woman at her one-roomed house then you are responsible for providing for her in exchange for sex.

Both women and men distinguished between women who exchanged sex for food and other goods from "prostitutes," although the distinction was not always consistent and clear. While sexual relationships with nonprimary partners that included some expectation of material help were reported to be frequent, women who were labeled "prostitutes" were generally those who gathered in bars and other urban settings specifically to seek one-time customers. The quote below by a 31-yearold married mother of two who ran a small hotel suggests that those who exchanged sex in bars and urban areas for money were vulnerable to doing so because of food insecurity: 
Most of the girls who work in bars or in town, and they don't have something to have for supper that day, so they decide to sell their bodies for food.

\section{Husbands' Death, Women's and Children's Food Insecurity, and Exchanging Sex for Food}

Some participants reported that women were especially vulnerable after the death of a husband or primary male partner, an event that could deprive them of access to food through loss of income, property, and other resources. Widows were often approached for sex in exchange for food and other subsistence goods shortly after the death of their spouse. For example, a 30-year-old male farmer with four children, explained how men in the community propositioned women following the death of a spouse:

Some act as only human beings would do and genuinely want to help out with the children, but for most they are usually more interested in helping these women with their children in exchange for sex. The motives of these women, they are looking for means of survival. Most of these women know that whatever man they give into, will at least give them something in exchange for sex.

Single women with children were specifically targeted for sex exchange following the death of a husband. This occurred even if they divulged their HIV status as a deterrent. As described by a 37-year-old widow with four children:

There are very many men who have approached me for sex, because most of them, when they see a single mother with many children, they think the mother will not be able to take care of the children, so they approach the woman...Even when she shows them her letters or documents about her HIV status, they're not scared. They still insist.

According to participants of both sexes, men who provided food and material support to women following the death of a spouse sometimes had an ulterior motive to take over the woman's property. One woman, 40, who was separated from her husband and had returned to her father's home, highlighted these concerns:

I know it happens to a lot of people...A woman had a husband who had HIV, the husband died. But then she meets another man who promises to take care of her children, but the man is not interested in taking care of her children. He's just interested in taking over the property that the husband left her.

On the other hand, participants also reported that when widows were left with land following the death of their husband, this could lead to increased food security and help to alleviate the need to engage in sexual relationships for food and other goods. "I know only one woman whose husband died and left her with some cows so she's the only one who has not resorted to that [exchange sex for food]," said a 34-year-old widow with five children. A man with two wives and six children to support also suggested that, when women were left with land and farm animals, they were protected from needing to engage in transactional sex:

There are some who do not have to do prostitution because their husbands may have died and left them well provided for with land, domestic animals, and if the woman plans for this property very well without getting another man-because another man will be interested in just spending her things-then she should be able to look after the children without any trouble.

According to several participants, the knowledge that a woman's husband died of HIV and that she herself might be HIV-positive did not always discourage men from offering food in exchange for sex. In other cases, some women were reluctant to discuss their HIV status with a new sexual partner because of their need to feed their children. The following quotes from two young, married women illustrate these points:

The men are from our village, so they're aware of her situation, I don't think she really tells them she has HIV, that she confirms to them. Because she has children, and they must eat, and they must be clothed, and they must go to school.

Like now that I'm here, there's not many people who know I have HIV. It's between me and my doctor, it's our secret. And for some of these women, they usually get married immediately after their husbands die without going for a check-up, so you can't know if they're sick or not...For most of these women, it's their secret, and you can't tell whether they have HIV or if they don't.

\section{Food Insecurity and Control over Condom Use}

A key theme in the interviews was that women with primary partners often lacked control over sexual relationships because of dependence on their male partners for food and other resources. The need to access food not only made it difficult for women to control the timing of sex, but also compromised their ability to assert control over condom use within these partnerships. In some cases, primary male sexual partners were reported to directly withhold food as a means of controlling the circumstance under which sex would occur. Women could also be threatened 
with violence if they insisted on condom use. These issues related to sexual control and condom use were illustrated by a 44-year-old woman whose husband died of AIDS and left her with four children to support:

If I'd insisted on condoms he would have been angry and would have beaten me, maybe. And the times I would really refuse to have sex with him, he would refuse to bring food and refuse to take care of the children. I tried it like two times, and both occasions he didn't bring home any food, he would go and spend the day elsewhere.

Certain norms pertaining to the roles of men and women within partnerships prevented some women, and particularly young women, from successfully negotiating condom use within their marriages or primary sexual relationships. According to a 34-year-old widow with five children between the ages of four and 16:

In our culture it's not acceptable that a woman should argue with the man, the word of the man is law, if you refuse to obey, you're chased from your husband's place. I tried to tell him about using condoms in a playful way, and I saw that it really put him out of sorts, he was very furious...In our culture, the woman is like the man's property, you do what the man says, he either commands you to eat, or not to eat. At that time, I was very young, and I didn't really have any way of being able to earn myself some money.

Women who tried to incorporate safe sexual practices at times encountered unsupportive male sexual partners and found themselves threatened with losing the security of the relationship, including access to food, if they insisted on condom use. Another 34-year-old widow, who was caring for her three children and three step-children, told of a friend whose husband tested positive for HIV and still refused to wear a condom:

He said it was painful with a condom. She didn't want to have live sex [sex without a condom] with him, but he threatened to divorce her if she didn't. He decided to see other women who were giving him live sex. So she decided to sleep with her husband without a condom since her children's future was at stake.

Since food insecurity often compromised a woman's ability to negotiate condom use and led to transactional sex as a survival tool, participants further described the context under which these transactions occurred to help explain HIV transmission dynamics. A few participants suggested that "housewives" or "mistresses" would not be able to insist on condoms because they did not have the skills to negotiate their use, unlike "prostitutes" reported to possess such skills. The quote below by one man demonstrates this distinction:
The ones who insist on using condoms are mostly prostitutes. But these housewives, few can demand condoms, compared with prostitutes...They are shy. They are not professionals on the job. Prostitutes sell sex, they encounter different people, that's why they need to demand condoms. But housewives of ours, few can demand condoms.

On the other hand, some women interviewed were able to successfully negotiate condom use with their partners or refuse to have sex without them. As stated by a woman who often used condoms with her husband: "Sometimes my husband insists that he doesn't want to use a condom. When I say no, we just go to sleep." Clinic staff or support from other women helped empower women to insist on condom use, as described by one female informant: "Unless they have gone outside and know what the situation is like, and have listened to people's experiences, then they don't have the control [over condom use]. But when they have seen that, then I think they have what it takes to insist. When they are sensitizing us [at the clinic], that's when you understand what is happening and you get the strength to control the situation."

\section{Staying in High-Risk Relationships for Food}

Several female and male participants discussed how women remained in abusive relationships because of their dependence on their male partners for food. One woman who lived with her parents and worked as a volunteer HIV educator explained how women stayed in abusive relationships because of a lack of other survival options, particularly when they had children to support:

They decide to stay with their husbands no matter how badly they're being treated, because their husbands are providing some food. What happens for some of the people I know is that the women are stuck in these relationships or stay with their husbands because they have children, and most of the time, the man, even if they're not providing much in terms of food, even if they bring a bunch of matoke [a traditional Ugandan food made from mashed, unripe bananas] without sauce, the women are happy to stay there. Because they're scared to go other places, because there they wouldn't even be getting the bunch of matoke.... the women, especially if they have children, don't have a choice.

The quote below, from a 46-year-old farmer and father of five, underscores the importance of providing women with sustainable options for food and economic security so that they do not need remain in abusive relationships to ensure the well-being of their children. It also highlights 
that dependence on male partners for food is most pronounced during the dry season, when food can be scarce [3]:

It usually happens to women who really do not have where to turn to for they know that even if they left, they would not be going to a better situation. There are also some other women that do not leave their abusive husbands if they have children. I am talking about their general welfare and more so about food, especially during the dry season, when there is no matoke.

The need to stay in abusive relationships for food and shelter was compounded when there was no other family nearby, as illustrated by the situation of a 32-year-old married woman with 5 children:

Sometimes we use condoms, but sometimes my husband insists, and when he insists, I have no choice, we have to have live sex. It's just so as to make sure he doesn't disturb me and I can stay with my children [participant begins crying]. And I don't have parents I can go to if the situation really becomes bad... Sometimes when I refuse he makes me sleep outside the house and therefore I have no choice but to give in, since I cannot go back home. For I do not have parents there, and yet I have only one brother who also stays very far away.

\section{Discussion}

Our findings indicate that there is a close relationship between food insecurity and risky sexual practices among women living with HIV in rural Uganda. To address this relationship, the gendered norms that facilitate or constrain access to sources of food must be considered [20, 24, 25]. As HIV continues to disproportionately affect women globally, research has shifted from a focus on individual risk-taking behaviors to socioeconomic and gender disparities that put women at risk for HIV [26-28]. Prior research has suggested that women's access to land, food, and legal protections are inextricably linked to HIV vulnerability [29].

In this study, we provide evidence of several mechanisms through which food insecurity exacerbates the difficulties HIV-infected women in sub-Saharan Africa face in maintaining safe sexual practices. Women who were food insecure, and in particular those who were recently widowed or who were raising children on their own, were routinely solicited for sex by men in their communities. Women who did not have access to land or consistent food sources were more vulnerable to engaging in sexual transactions to alleviate their own hunger and that of their children. Women who were dependent on their primary partners for food had little negotiating power to insist on condom use within their sexual relationships. We also found a clear relationship between women's food insecurity and remaining in an abusive relationship; women continued to expose themselves to physical and psychological risk out of fear that they would lose access to food and land for food production. As is the case in other parts of the world, women in Uganda often have difficulty leaving violent relationships as a result of either unreliable social safety nets or lack of economic opportunities for women and children. Some programs in Uganda have demonstrated success in poverty alleviation using microcredit as part of the social safety net; however, these programs remain unavailable to the vast majority of women in Uganda. In addition to expanding microcredit programs for women, integration of gender-based violence and HIV prevention programs for men are critical to reduce HIV transmission and gender disparities [30].

While many women in parts of sub-Saharan Africa, including Uganda, typically lack control over food sources and own very little land, they are nonetheless responsible for the majority of food production and agricultural labor [29]. Women are at risk of losing access to land and other resources through divorce or widowhood, exacerbating their already precarious economic situation [29]. The Ugandan women's movement had some success at advocating for women's land rights in the 1998 Land Act and some positive changes were made, particularly involving the legalization of land purchase by women [31]. However, the realization of these rights has lagged, in part, due to poor infrastructure support for women to access legal services and adjudicate land disputes [29]. In addition, customary land tenure systems and lack of economic resources may present additional barriers for women to access the legal system to support their rights to land [31]. Thus, in addition to women's legal protection to the land they live and farm, community-based activities that promote knowledge regarding these legal rights and how to access the law in land-related conflicts must also be included in local public health programs. Guaranteeing women's access to land titles will help ensure that they are not evicted from their land following the loss of a spouse and will provide them with support to leave abusive relationships [32].

The link between gender inequity and food insecurity reflects wider social and economic inequities, including women's lack of security over familial assets [33, 34]. To reduce the burden of HIV infection in African settings, health policymakers need to ensure that women's access to food and land for food production is a public health priority [35]. The implementation of food support programs, with a 
particular focus targeting households headed by single and widowed women and those with children, must become an integral component of the national HIV prevention strategy in order to alleviate some of the tough choices women confront in their sexual decision-making [32].

Implementing and expanding microcredit programs for women will help to address gender and socioeconomic inequalities. These programs help to strengthen economic bonds among women in order to help reduce women's reliance on male partners for access to food and means of food production [36, 37]. In addition, expanding educational opportunities for women and girls will provide improved employment opportunities for women and may decrease risky sexual practices both of which may ultimately improve gender power imbalances. In general, multi-level interventions that simultaneously target men, women, village leaders, and service providers are likely to be most effective [38]. These interventions should address structural barriers to food security, including discriminatory cultural and social practices, and should incorporate legal and policy reforms to promote women's rights [39].

There are several limitations in this study. Within Uganda and other parts of sub-Saharan Africa, populations are highly heterogeneous, and thus our findings may not generalize to other settings. The relationship and specific mechanisms through which food insecurity may play a role in HIV vulnerability must therefore be regarded as a priority for future research in other low-resource settings. Our sample included only HIV-positive individuals. It is therefore difficult to determine whether food insecurity preceded or followed HIV-infection, and the extent to which similar mechanisms would be found in HIV-negative populations. Other research, however, has documented links between food insecurity and lack of control over sexual decision-making and transactional sex among both HIV-negative and HIV-positive samples [17, 18]. In addition, some of the quotes referenced the behavior of others, rather than providing first-person accounts of experiences. While this may limit the veracity of the reports, discussing sensitive personal information in the third person is a common cultural practice in the study population, and findings are also supported by personal vignettes. Finally, sexual relationships are complex and likely more nuanced than reported here, yet the extent to which food insecurity was emphasized as an impediment to safe sexual practices among our informants was striking.

\section{Conclusion}

This study provides evidence of several mechanisms through which food insecurity led women to engage in risky sexual practices. Hunger often formed the basis for sexual transactions between men and women, and made it difficult for women to insist on condom use. Sex under these conditions was inextricably linked to gendered power relations that increased women's vulnerability to violence, coercion and conditions facilitating HIV transmission. Implementing programs and policies that minimize women's reliance on men for food security by ensuring their access to food and land for food production will likely help reduce the spread of HIV, support women's sexual health, and sustain the overall well-being, of women, men, and their children.

Acknowledgments This study was funded by NIMH K23 MH079713-01, NIMH RO-1 54907, the Meyer Family Foundation and the Hellman Family Awards for Early-Career Faculty. Dr. Bangsberg received support from K24 MH87227. The authors wish to thank Kathleen McCartney, Janet Ayebare, Nozmu Mukiibi, and Nneka Emenyonu for their invaluable contributions to this research.

\section{Conflict of interest statement None.}

Open Access This article is distributed under the terms of the Creative Commons Attribution Noncommercial License which permits any noncommercial use, distribution, and reproduction in any medium, provided the original author(s) and source are credited.

\section{References}

1. Normen L, Chan K, Braitstein P, et al. Food insecurity and hunger are prevalent among HIV-positive individuals in British Columbia, Canada. J Nutr. 2005;135(4):820-5.

2. Lartey A. Maternal and child nutrition in Sub-Saharan Africa: challenges and interventions. Proc Nutr Soc. 2008;67(1):105-8.

3. Haile M. Weather patterns, food security and humanitarian response in sub-Saharan Africa. Philos Trans R Soc Lond B Biol Sci. 2005;360(1463):2169-82.

4. United Nations Economic Commission for Africa. Mitigating the impact of HIV/AIDS on smallholder agriculture, food security and rural livelihoods in Southern Africa: challenges and action plan: United Nations, South African Office; 2006. http://www. uneca.org/srdc/sa/publications/HIV-AIDSandAgriculture.pdf. Accessed 23 Sept 2008.

5. Gillespie S, Kadiyala S. HIV/AIDS and Food and Nutrition Security: from evidence to action; 2005. http://www.ifpri.org/ pubs/fpreview/pv07/pv07.pdf. Accessed 23 Sept 2008.

6. Seume-Fosso E, Rajabiun S, Cogill B, Elder L, Castleman T, Sheckler A. Food and Nutrition Technical Assistance. HIV/ AIDS: a guide for nutritional care and support; 2004. http://www. fantaproject.org/publications/HIVguide.shtml. Accessed $23 \mathrm{Sept}$ 2008.

7. Montgomery K. Nutrition and HIV-positive pregnancy. J Perinat Educ. 2003;12(1):42-7.

8. Weiser S, Fernandes K, Brandson E, Lima V, Anema A, Bangsberg D. The impact of food insecurity and body mass index on mortality among HIV-infected individuals first initiating HAART. JAIDS. 2009;52(3):342-9.

9. De Vogli R, Birbeck G. Potential impact of adjustment policies on vulnerability of women and children to HIV/AIDS in subSaharan Africa. J Health Popul Nutr. 2005;23(2):105-20.

10. Nyindo M. Complementary factors contributing to the rapid spread of HIV-I in sub-Saharan Africa: a review. East Afr Med J. 2005;82(1):40-6. 
11. Mill JE, Anarfi JK. HIV risk environment for Ghanaian women: challenges to prevention. Soc Sci Med. 2002;54(3):325-37.

12. Fields-Gardner C, Fergusson P. Nutrition intervention in the care of persons with human immunodeficiency virus infection: position of the American Dietetic Association and Dietitians of Canada. Can J Diet Pract Res. 2004;65(3):132-5.

13. Rajaraman D, Russell S, Heymann J. HIV/AIDS, income loss and economic survival in Botswana. AIDS Care. 2006;18(7):656-62.

14. Buseh AG, Glass LK, McElmurry BJ. Cultural and gender issues related to HIV/AIDS prevention in rural Swaziland: a focus group analysis. Health Care Women Int. 2002;23(2):173-84.

15. Leclerc-Madlala S. Age-disparate and intergenerational sex in southern Africa: the dynamics of hypervulnerability. AIDS. 2008;22(4):S17-25.

16. Maganja R, Maman S, Groves A, JK M. Skinning the goat and pulling the load: transactional sex among youth in Dar es Salaam, Tanzania. AIDS Care. 2007;19(8):974-81.

17. Oyefara J. Food insecurity, HIV/AIDS pandemic and sexual behaviour of female commercial sex workers in Lagos metropolis, Nigeria. SAHARA J. 2007;4(2):626-35.

18. Weiser SD, Leiter K, Bangsberg DR, et al. Food insufficiency is associated with high-risk sexual behavior among women in Botswana and Swaziland. PLoS Med. 2007;4(10):1589-97. discussion 1598.

19. Hawkins K, Price N, Mussa F. Milking the cow: Young women's construction of identity and risk in age-disparate transactional sexual relationships in Maputo, Mozambique. Glob Public Health. 2009;4(2):169-82.

20. Dunkle KL, Jewkes R, Nduna M, et al. Transactional sex with casual and main partners among young South African men in the rural Eastern Cape: prevalence, predictors, and associations with gender-based violence. Soc Sci Med. 2007;65(6):1235-48.

21. Miles M, Huberman A. Qualitative data analysis. Thousand Oaks: Sage Publications; 1994.

22. Strauss A, Corbin J. Basics of qualitative research: grounded theory procedures and techniques. Thousand Oaks: Sage Publications; 1990.

23. Krefting L. Rigor in qualitative research: the assessment of trustworthiness. Am J Occup Ther. 1991;45:214-22.

24. Dworkin S, Ehrhardt A. Going Beyond "ABC" to Include "GEM": critical reflections on progress in the HIV/AIDS epidemic. Am J Public Health. 2007;97(1):13-8.

25. Moore A, Awusabo-Asare K, Madise N, John-Langba J, KumiKyereme A. Coerced first sex among adolescent girls in subSaharan Africa: prevalence and context. Afr J Reprod Health. 2007;11(3):62-82.

26. Smith K, Watkins S. Perceptions of risk and strategies for prevention: responses to HIV/AIDS in rural Malawi. Soc Sci Med. 2005;60(3):649-60.
27. Anglewicz P, Bignami-Van Assche S, Clark S, Mkandawire J. HIV risk among currently married couples in rural Malawi: what do spouses know about each other? AIDS Behav. 2008;14(1): 103-12.

28. Maman S, Mbwambo J, Hogan N, Kilonzo G, Campbell J, Weiss E. HIV-positive women report more lifetime partner violence: findings from a voluntary counseling and testing clinic in Dar es Salaam, Tanzania. Am J Public Health. 2002;92(8):1331-7.

29. Quisumbing A, Meinzen-Dick R, Smith L. Increasing the effective participation of women in food and nurtrition security in Africa. Assuring food and nutrition security in Africa by 2020: prioritizing action, strengthening actors, and facilitating partnerships. Vol Kampala, Uganda: International Food Policy Research Institute; 2004

30. Kalichman SC, Simbayi LC, Cloete A, et al. Integrated genderbased violence and HIV Risk reduction intervention for South African men: results of a quasi-experimental field trial. Prev Sci Sep. 2009;10(3):260-9.

31. Tripp AM. Women's movements, customary law, and Land Rights in Africa: the case of Uganda. Afr Stud Q. Spring 2004;7(4). http://www.africa.ufl.edu/asq/v7/v7i4a1.htm.

32. Gausset Q. AIDS and cultural practices in Africa: the case of the Tonga (Zambia). Soc Sci Med. 2001;52(4):509-18.

33. Krishnan S, Dunbar M, Minnis A, Medlin C, Gerdts C, Padian N. Poverty, gender inequities, and women" Äôs risk of human immunodeficiency virus/AIDS. Ann N Y Acad Sci. 2008;1136: 101-10.

34. Langen T. Gender power imbalance on women's capacity to negotiate self-protection against HIV/AIDS in Botswana and South Africa. Afr Health Sci. 2005;5(3):188-97.

35. Hyder AA, Maman S, Nyoni JE, et al. The pervasive triad of food security, gender inequity and women's health: exploratory research from sub-Saharan Africa. Afr Health Sci. 2005;5(4): 328-34.

36. Kim J, Watts C. Gaining a foothold: tackling poverty, gender inequality, and HIV in Africa. Br Med J. 2005;331(7519):769-72.

37. Pronyk PM, Hargreaves JR, Kim JC, et al. Effect of a structural intervention for the prevention of intimate-partner violence and HIV in rural South Africa: a cluster randomised trial. Lancet. 2006;368(9551):1973-83.

38. Coates T, Richter L, Caceres C. Behavioural strategies to reduce HIV transmission: how to make them work better. Lancet. 2008;372(9639):669-84.

39. Holveck J, Ehrenberg J, Ault S, Rojas R, Vasquez J, Cerqueira M. Prevention, control, and elimination of neglected diseases in the Americas: pathways to integrated, inter-programmatic, intersectoral action for health and development. BMC Public Health. 2007;7:6 